\title{
Nonlinear Control of a Polymerization CSTR with Singular Characteristic Matrix
}

\author{
Masoud Soroush and Costas Kravaris \\ Dept. of Chemical Engineering, University of Michigan, Ann Arbor, MI 48109
}

\begin{abstract}
This experimental work concerns the multivariable nonlinear control of a pilotsize continuous polymerization reactor with generically singular characteristic matrix. The control problem is to control conversion and temperature in a continuous stirred tank reactor by manipulating two coordinated flow rates (reactor residence time) and two coordinated heat inputs. A nonlinear controller is synthesized within the framework of the globally linearizing control $(G L C)$ method and is implemented on a microcomputer. Conversion is inferred from on-line measurements of density and temperature. A key feature of the control problem is that its characteristic matrix is generically singular. Singularity of the characteristic matrix is handled by using a dynamic input/output linearizing state feedback rather than a static feedback. $A$ reduced-order observer is used to calculate the monomer, initiator, and solvent concentration estimates, which are needed for the calculation of controller action. In the presence of active state and input constraints, the reactor-startup and setpointtracking performance of the controller is evaluated through experimental runs.
\end{abstract}

\section{Introduction}

Apart from safety concerns, the principal motives for control of polymerization reactors are high yield and high product quality. Amrehn (1977) reported that the polymerization industry significantly lags behind many industries in using computers for control purposes and highlighted some of the potential benefits that polymerization industry can receive from the implementation of advanced control strategies for polymerization reactors. Since that time, the area of polymerization reactor control has significantly evolved (Elicabe and Meira, 1988; MacGregor, 1986; Ray, 1992). Computers now play an important role in control of polymerization reactors and their use is expanding (Ray, 1992).

However, the inherent characteristics of polymerization reactors, such as their complex nonlinear and strongly interactive behavior and the complexity of the relationships between reactor operating conditions and product properties, have mainly hindered the effective implementation of advance control methods for polymerization reactors. One very important problem, a consequence of the above characteristics, is the

Current address of M. Soroush: Chemical Engineering Dept., Drexel University, Philadelphia, PA 19104 inadequacy of on-line sensors with fast sampling rate and small time delay. A considerable research effort has been devoted to address this problem, leading to some progress (see Chien and Penlidis, 1990; Elicabe and Meira, 1988; Ray, 1992 and the references therein). Despite progress, the inadequacy of currently-available on-line sensors is still a major obstacle to efficient control of polymerization reactors.

Because of the complex nature of polymerization reactors (Elicabe and Meira, 1988; Ray, 1992; Tirrell et al., 1987), a few real-time, closed-loop polymerization-reactor-control studies have been carried out and reported in the literature (see Soroush and Kravaris, 1992, 1993 and the references therein). The difficulty involved in getting on-line measurements in the viscous polymerizing mixtures has limited these studies mainly to temperature and pressure control.

This article presents another polymerization-reactor-control study from a series of real-time implementation studies of the globally linearizing control (GLC) method for polymerization reactors, some of which have already been published (Soroush and Kravaris, 1992, 1993).

In this study, the GLC method is implemented experimentally to control conversion and temperature in a continuous stirred tank polymerization reactor (CSTR), in which the so- 
lution polymerization of methyl methacrylate (MMA) takes place. The solvent and initiator are toluene and azo-bis-isobutyronitrile (AIBN), respectively. The control of temperature and conversion is achieved by manipulating two coordinated heat inputs and two coordinated flow rates (reactor residence time). Therefore, there are four manipulated inputs and two controlled outputs. A key feature of this control problem is that its characteristic matrix is generically singular. This work is an experimental application of a very recent study by Daoutidis and Kumar (1994) on the synthesis of feedback control systems for general multivariable nonlinear processes with singular characteristic matrix. Furthermore, it is the first realtime control study in which a multiinput multioutput (MIMO) nonlinear process with singular characteristic matrix is controlled by a nonlinear model-based controller.

First, the experimental system is described. After constructing a mathematical model of the process, a nonlinear controller is synthesized within the GLC framework and the issues involved in the real-time implementation of the control law are discussed. Finally, performance of the controller is examined through experimental runs.

\section{Polymerization Reactor System}

Figure 1 shows the pilot-size polymerization-reactor system. This experimental system includes all the components of our CSTR experimental system (Soroush and Kravaris, 1993) and differs in the following respects: the flow rate of the initiator

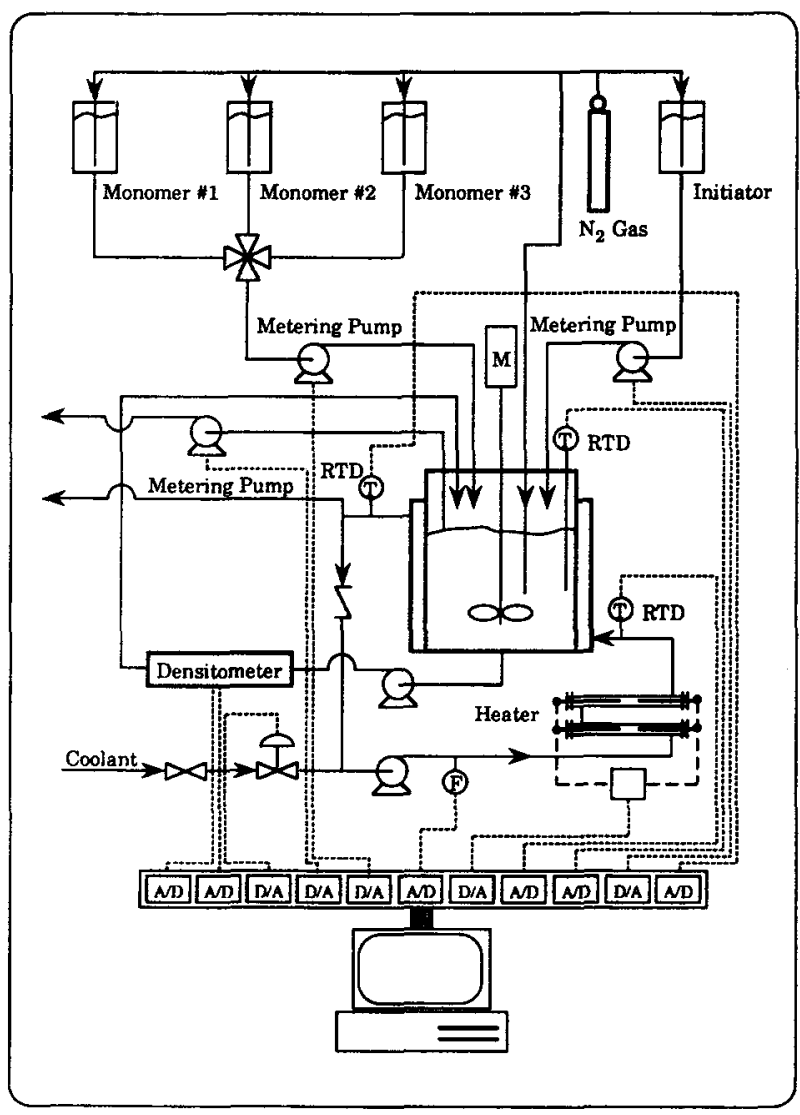

Figure 1. Polymerization-reactor system.
Table 1. Other Parameters of the Reactor System

$T_{\text {in }}=2.952 \times 10^{2} \mathrm{~K}$
$F_{m_{\max }}=1.000 \times 10^{-6} \mathrm{~m}^{3} \cdot \mathrm{s}^{-1}$
$V=1.200 \times 10^{-3} \mathrm{~m}^{3}$
$F_{i}=1.500 \times 10^{-8} \mathrm{~m}^{3} \cdot \mathrm{s}^{-1}$
$T_{\infty}=2.952 \times 10^{2} \mathrm{~K}$

stream is constant, the flow rate of the monomer stream is not constant and is adjusted by the monomer metering pump, and the flow rate of the product stream is also not constant and is adjusted by the product metering pump in coordination with the monomer-stream flow rate. A detailed description of the components of the polymerization-reactor system is given in Soroush and Kravaris (1993). Other parameters of the system are given in Table 1.

The dynamics of the control elements are much faster than the dynamics of the reactor and the jacket. The fast dynamics are neglected in the model development. Except for the control valve and the monomer metering pump, the steady-state input/ output behavior of the other control elements is linear. The nonlinear steady-state behavior (signal/flow) can be represented by quadratic equations, which are used in calculating the actual flow rates from the corresponding digital signals and vice versa.

\section{Mathematical Model}

For this polymerization system, the rate expressions $\left(R_{m}\right.$ $R_{i}, R_{H}$ ) are the same as in Soroush and Kravaris (1993), and so are the physical properties, reaction rate constants, and gel and glass effect correlations.

Volume of the reacting mixture in the reactor remains constant during operation (experimental design ensures this). Therefore, the actual volumetric flow rate of the product stream, $F$, is related to the total inlet volumetric flow rate, $\left(F_{i}+F_{m}\right)$, by (Schmidt and Ray, 1981):

$$
F=\left(F_{i}+F_{m}\right)\left(1+\bar{\epsilon} x_{p}\right)
$$

where $x_{p}$ is the solvent-free mass-fraction of polymer in the reactor, given by $x_{p}=\mu_{1} /\left(M_{m} C_{m}+\mu_{1}\right)$, and $\bar{\epsilon}$ is a mean value of the polymerization-volume-expansion factor over a desired operating temperature range.

Under the same assumptions as in Soroush and Kravaris (1993), mole balances on the monomer, initiator, and solvent, a mass balance on the dead polymer, and energy balances for the reactor and its jacket give a dynamic model with the state variables $C_{m}, C_{i}, C_{s}, \mu_{1}, T$, and $T_{j}$.

Practical considerations suggest that before calculating a GLC controller, a process model should be recast so that all the "useful" process measurements appear as state variables (Soroush and Kravaris, 1993). Here, in addition to the controlled outputs ( $T$ and $x_{p}$ ), we can measure only jacket temperature, which is one of the state variables. Since $\partial x_{p} / \partial \mu_{1} \neq 0$, the state variable $\mu_{1}$ can be replaced by the conversion, $x_{p}$, and therefore, the process dynamics can be described equivalently by a model with the state variables $C_{m}, C_{i}, C_{s}, x_{p}, T$, and $T_{j}$ : 


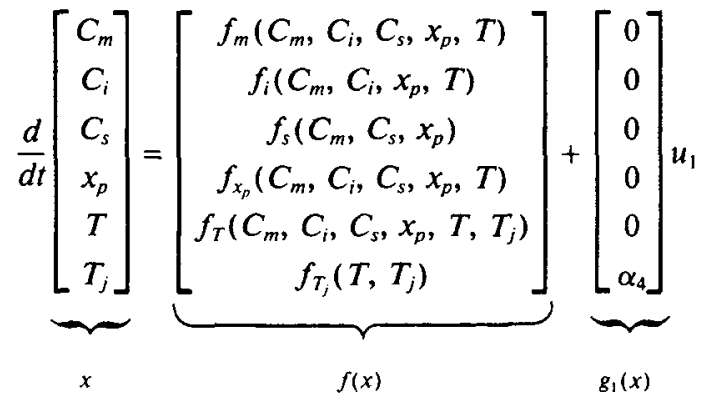

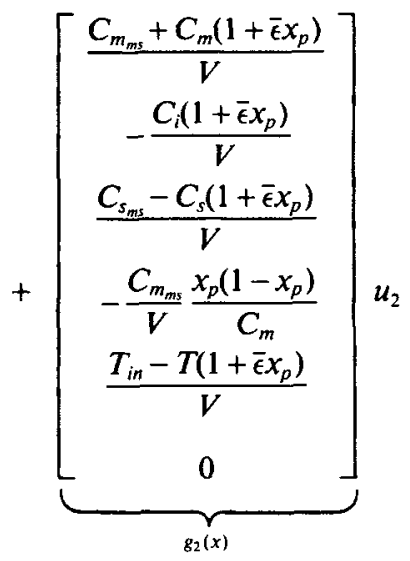

where $u_{1}=\boldsymbol{P}-F_{c w} c_{w} \rho_{w}\left(T_{j}-T_{c w}\right)$, which is indeed the net rate of heat addition to the jacket circulating system by the inlet coolant and heater, $u_{2}=F_{m}$ (flow rate of inlet monomer stream);

$f_{m}\left(C_{m}, C_{i}, C_{s}, x_{p}, T\right)=R_{m}\left(C_{m}, C_{i}, C_{s}, x_{p}, T\right)-\frac{C_{m}\left(1+\bar{\epsilon} x_{p}\right)}{V} F_{i}$

$f_{i}\left(C_{i}, x_{p}, T\right)=R_{i}\left(C_{i}, T\right)+\frac{C_{i_{i s}}-C_{i}\left(1+\bar{\epsilon} x_{p}\right)}{V} F_{i}$

$f_{s}\left(C_{s}, x_{p}\right)=\frac{C_{s_{i s}}-C_{s}\left(1+\bar{\epsilon} x_{p}\right)}{V} F_{i}$

$f_{x_{p}}\left(C_{m}, C_{i}, C_{s}, x_{p}, T\right)=-\frac{\left(1-x_{p}\right)}{C_{m}} R_{m}\left(C_{m}, C_{i}, C_{s}, x_{p}, T\right)$

$f_{T}\left(C_{m}, C_{i}, C_{s}, x_{p}, T, T_{j}\right)=\alpha_{0} R_{H}\left(C_{m}, C_{i}, C_{s}, x_{p}, T\right)$

$$
+\alpha_{1}\left(T_{j}-T\right)+\alpha_{1_{2}}\left(T_{\infty}-T\right)+\frac{T_{\text {in }}-T\left(1+\bar{\epsilon} x_{p}\right)}{V} F_{i}
$$

$f_{T_{j}}\left(T, T_{j}\right)=\alpha_{2}\left(T-T_{j}\right)+\alpha_{3}\left(T_{\infty}-T_{j}\right)$

Note that, as in Soroush and Kravaris (1993), for simplicity of the above mathematical model used in the controller synthesis, the volume expansion factor and the density of the reacting mixture were assumed to be constant (a mean value of the volume expansion factor was used). In the above model, the heat losses from the reactor and the sensor circulating system to the environment are accounted for.

\section{Parameter estimation}

The least-squares estimates of the parameters $\alpha_{1,}$ and $\alpha_{1,}$ are calculated as follows:
- Estimation of $\theta \stackrel{\Delta}{=} \alpha_{1_{1}} / \alpha_{1_{2}}$ : Under the conditions of the only solvent in the reactor, steady-state ( $T, T_{d}$, and $T_{j}$ constant), batch operation (no feed into and no product out of the reactor), and no inlet cooling water $\left(F_{c w}=0\right)$, according to the model of Eq. 1, the dependence of the difference in the reactor temperature and room temperature $\left(T-T_{\infty}\right)$ on the difference in the jacket temperature and reactor temperature $\left(T_{j}-T\right)$ is linear. In this case, the slope of the fitted regression line to the $\left(T-T_{\infty}\right)$ vs. $\left(T_{j}-T\right)$ data points, which correspond to different settings of the heater power $\boldsymbol{P}$, gives the least-squares estimate of $\theta=5.01$.

- Estimation of $\alpha_{1_{1}}+\alpha_{1_{2}}$ : Under the conditions of only solvent in the reactor, and batch operation (no feed into and no product out of the reactor), according to the model of Eq. 1, when there is a step change in the jacket temperature $\left(T_{j}\right)$, $\ln \left[\left(T-\left[T_{\infty}+\theta T_{c w}\right] /[1+\theta]\right) /\left(T_{0}-\left[T_{\infty}+\theta T_{c w}\right] /[1+\theta]\right)\right]$ is a linear function of time. The step change in the jacket temperature is achieved by switching the control valve position from fully closed to fully open under no power to the heater. In this case, the slope of the fitted regression line to $\ln \left[\left(T-\left[T_{\infty}+\theta T_{c w}\right] /\right.\right.$ $\left.[1+\theta]) /\left(T_{0}-\left[T_{\infty}+\theta T_{c w}\right] /[1+\theta]\right)\right]$ vs. time data points gives the least-squares estimate of $\alpha_{1_{1}}+\alpha_{1_{2}}\left(\alpha_{1_{1}}+\alpha_{1_{2}}=0.0228 \mathrm{~s}^{-1}\right)$.

- Calculation of $\alpha_{1_{1}}$ and $\alpha_{1_{2}}: \alpha_{1_{1}}=0.0190 \mathrm{~s}^{-1}$ and $\alpha_{1_{2}}=0.0038$ $s^{-1}$.

The values of the parameters $\alpha_{2}, \alpha_{3}$, and $\alpha_{4}$ are the same as those used in (Soroush and Kravaris, 1993).

\section{Synthesis of the Control Law for the Process}

To synthesize a nonlinear controller within the GLC framework for this process, we follow the general approach given in (Soroush and Kravaris, 1993).

The controlled outputs are: $y_{1}=T$ and $y_{2}=\mu_{1} /\left(M_{m} C_{m}+\mu_{1}\right)$. The conversion, $x_{p}$, as in Soroush and Kravaris (1993) is inferred from the on-line measurements of density and temperature.

For the system of Eq. 1, since

$$
\begin{aligned}
& L_{g_{1}} T=0, \quad L_{g_{2}} T=\frac{T_{\mathrm{in}}-T\left(1+\bar{\epsilon} x_{p}\right)}{V} \not \equiv 0, \\
& L_{g_{1}} x_{p}=0, \quad L_{g_{2}} x_{p}=-\frac{C_{m_{m m}}}{V} \frac{x_{p}\left(1-x_{p}\right)}{C_{m}} \neq 0,
\end{aligned}
$$

and therefore, the relative orders $r_{1}=1$ and $r_{2}=1$, and the characteristic matrix

$$
C(x)=\left[\begin{array}{ll}
0 & L_{g_{2}} T \\
0 & L_{g_{2}} x_{p}
\end{array}\right],
$$

which is generally singular.

Remark. If the characteristic matrix is generally singular, one may not be able to calculate a static input/output linearizing state feedback, and a dynamic input/output linearizing state feedback may have to be used (Kravaris and Soroush, 1990). In a very recent study, Daoutidis and Kumar (1994) have derived controller synthesis formulas, which can be used for general minimum-phase nonlinear processes with singular characteristic matrix. 
In this experimental study, the characteristic matrix of the system is generically singular, and therefore, a dynamic input/ output linearizing state feedback is used. This approach can be interpreted physically as redefining the second manipulated input: the rate of change of monomer flow rate is used as the second manipulated input, instead of the monomer flow rate, $F_{m}$, itself. Thus, the new second manipulated input $\tilde{u}_{2}$ is related to the monomer flow rate, $F_{m}$, according to $\dot{F}_{m}=\tilde{u}_{2}$.

With this modification, the polymerization model of Eq. 1 becomes (dimension of the process model increases by one):

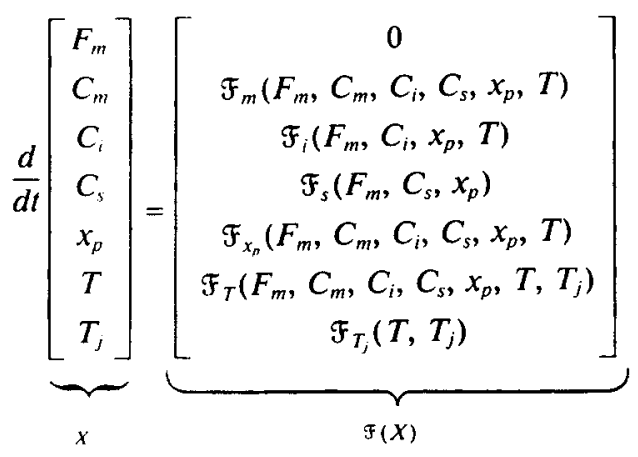

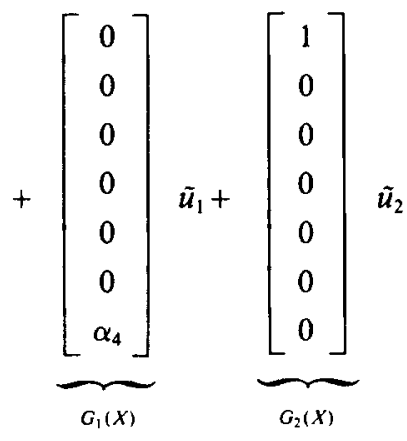

where $\tilde{u}_{1}=u_{1}$,

$$
\begin{gathered}
\mathcal{F}_{m}\left(F_{m}, C_{m}, C_{i}, C_{s}, x_{p}, T\right)=f_{m}\left(C_{m}, C_{i}, C_{s}, x_{p}, T\right) \\
+\frac{C_{m_{m s}}-C_{m}\left(1+\bar{\epsilon} x_{p}\right)}{V} F_{m} \\
\mathcal{F}_{i}\left(F_{m}, C_{i}, x_{p}, T\right)=f_{i}\left(C_{i}, x_{p}, T\right)-\frac{C_{i}\left(1+\bar{\epsilon} x_{p}\right)}{V} F_{m} \\
F_{s}\left(F_{m}, C_{s}, x_{p}\right)=f_{s}\left(C_{s}, x_{p}\right)+\frac{C_{s_{m s}}-C_{s}\left(1+\bar{\epsilon} x_{p}\right)}{V} F_{m} \\
\mathscr{F}_{x_{p}}\left(F_{m}, C_{m}, C_{i}, C_{s}, x_{p}, T\right)=f_{x_{p}}\left(C_{m}, C_{i}, C_{s}, x_{p}, T\right) \\
-\frac{C_{m_{m s}}}{V} \frac{x_{p}\left(1-x_{p}\right)}{C_{m}} F_{m}
\end{gathered}
$$$$
\mathcal{F}_{T}\left(F_{m}, C_{m}, C_{l}, C_{s}, x_{p}, T, T_{j}\right)=f_{T}\left(C_{m}, C_{i}, C_{s}, x_{p}, T, T_{j}\right)
$$

$$
+\frac{T_{\text {in }}-T\left(1+\bar{\epsilon} x_{p}\right)}{V} F_{m}
$$

$\mathcal{F}_{T_{l}}\left(T, T_{j}\right)=f_{T_{i}}\left(T, T_{j}\right)$

For the modified process model of Eq. 2, since:

$$
\begin{gathered}
L_{G_{1}} T=0, \quad L_{G_{2}} T=0, \quad L_{G_{1}} x_{p}=0, \quad L_{G_{F}} x_{p}=0 \\
L_{G_{1}} L_{\mathfrak{F}} T=\alpha_{1} \alpha_{4} \neq 0, \quad L_{G_{2}} L_{\mathfrak{F}} T=\frac{T_{\text {in }}-T\left(1-\bar{\epsilon} x_{p}\right)}{V} \not 0, \\
L_{G_{1}} L_{\mathfrak{F}} x_{p}=0, \quad L_{G_{2}} L_{\mathfrak{F}} x_{p}=-\frac{C_{m_{m s}}}{V} \frac{x_{p}\left(1-x_{p}\right)}{C_{m}} \neq 0,
\end{gathered}
$$

and therefore, the relative orders $r_{1}=2$ and $r_{2}=2$, and the characteristic matrix

$$
C(X)=\left[\begin{array}{cc}
L_{G_{1}} L_{\mathfrak{F}} T & L_{G_{2}} L_{\mathfrak{f}} T \\
0 & L_{G_{2}} L_{\mathfrak{F}} x_{p}
\end{array}\right]
$$

which is nonsingular, and thus, is straightforward to calculate an input/output linearizing controller. In particular, we implement the following nonlinear controller (Soroush and Kravaris, 1993):

$$
\begin{aligned}
& v_{1}=y_{s p_{1}}+K_{c_{1}}\left(y_{s p_{1}}-T+\frac{1}{\tau_{I_{1}}} \int_{0}^{t}\left[y_{s p_{1}}(\tau)-T(\tau)\right] d \tau\right) \\
& v_{2}=y_{s p_{2}}+K_{c_{2}}\left(y_{s p_{2}}-x_{p}+\frac{1}{\tau_{I_{2}}} \int_{0}^{t}\left[y_{s p_{2}}(\tau)-x_{p}(\tau)\right] d \tau\right) \\
& \begin{cases}\frac{d F_{m}}{d t}=\tilde{u}_{2}, & F_{m}(0)=0 \\
\frac{d \hat{C}_{m}}{d t}=F_{m}\left(F_{m}, \hat{C}_{m}, \hat{C}_{i}, \hat{C}_{s}, x_{p}, T\right), & \hat{C}_{m}(0)=C_{m}(0) \\
\frac{d \hat{C}_{i}}{d t}=F_{i}\left(F_{m}, \hat{C}_{i}, x_{p}, T\right), & \hat{C}_{i}(0)=C_{i}(0) \\
\frac{d C_{s}}{d t}=F_{s}\left(F_{m}, \hat{C}_{s}, x_{p}\right), & \hat{C}_{s}(0)=C_{s}(0) \\
\tilde{u}_{1}=\Psi_{1}\left(v, F_{m}, \Psi_{2}, \hat{C}_{m}, \hat{C}_{i}, \hat{C}_{s}, x_{p}, T, T_{j}\right) & \\
\tilde{u}_{2} & =\Psi_{2}\left(v_{2}, F_{m}, \hat{C}_{m}, \hat{C}_{i}, \hat{C}_{s}, x_{p}, T\right)\end{cases}
\end{aligned}
$$

where

$$
\Psi_{2}\left(v_{2}, F_{m}, \hat{C}_{m}, \hat{C}_{i}, \hat{C}_{s}, x_{p}, T\right)=\frac{v_{2}-x_{p}-\sum_{i=1}^{2} \beta_{2 i}^{2} L_{\mathfrak{f}}^{i} x_{p}}{\beta_{22}^{2} L_{G_{2}} L_{F} x_{p}},
$$

$$
\begin{array}{r}
\Psi_{1}\left(v, F_{m}, \Psi_{2}, \hat{C}_{m}, \hat{C}_{i}, \hat{C}_{s}, x_{p}, T, T_{j}\right)=\frac{v_{1}-T-\sum_{i=1}^{2} \beta_{1 i}^{1} L_{\xi}^{i} T}{\beta_{12}^{1} \alpha_{1} \alpha_{4}} \\
+\frac{L_{G_{2}} L_{\xi} T}{\alpha_{1} \alpha_{4}} \Psi_{2}\left(v_{2}, F_{m}, \hat{C}_{m}, \hat{C}_{i}, \hat{C}_{s}, x_{p}, T\right),
\end{array}
$$

and $\beta_{i j}^{i}, K_{i,}$, and $\tau_{l,}$ are the controller tunable parameters. The controller of Eq. 3 induces the decoupled linear input/output behavior: 


$$
\begin{aligned}
& \beta_{12}^{1} \frac{d^{3} y_{1}}{d t^{3}}+\beta_{11}^{1} \frac{d^{2} y_{1}}{d t^{2}}+\left(K_{c_{1}}+1\right) \frac{d y_{1}}{d t}+\frac{K_{c_{1}}}{\tau_{l_{1}}} y_{1}=K_{c_{1}}\left(\frac{d y_{s p_{1}}}{d t}+\frac{1}{\tau_{I_{1}}} y_{s p_{1}}\right) \\
& \beta_{22}^{2} \frac{d^{3} y_{2}}{d t^{3}}+\beta_{21}^{2} \frac{d^{2} y_{2}}{d t^{2}}+\left(K_{c_{2}}+1\right) \frac{d y_{2}}{d t}+\frac{K_{c_{2}}}{\tau_{l_{2}}} y_{2}=K_{c_{2}}\left(\frac{d y_{s p_{2}}}{d t}+\frac{1}{\tau_{l_{2}}} y_{s p_{2}}\right)
\end{aligned}
$$

to the closed-loop system. The nonlinear controller of Eq. 3 consists of two single-input single-output (SISO) PI controllers, a state feedback, and a reduced-order state observer,

$$
\begin{aligned}
v_{l}^{\prime \prime}\left(t_{k}\right)=v_{l}^{\prime \prime}\left(t_{k-1}\right)+ & K_{c_{\ell}}\left[\left(\frac{\Delta t}{\tau_{l_{f}}}+1\right)\left[y_{s p_{\mathrm{f}}}\left(t_{k}\right)-y_{p}\left(t_{k}\right)\right]\right. \\
& \left.-\left[y_{s p_{p}}\left(t_{k-1}\right)-y_{P}\left(t_{k-1}\right)\right]\right], \quad \ell=1,2
\end{aligned}
$$

where $\Delta t$ is the sampling period. Equation 10 is the velocity form of a digital PI controller.

- $\hat{C}_{m}\left(t_{k}\right), \hat{C}_{i}\left(t_{k}\right)$, and $\hat{C}_{s}\left(t_{k}\right)$ are calculated from numerical integration of the last three differential equations in Eq. 3 using the Runge-Kutta-Gill method (integration step-size $=$ sampling period).

- $\dot{F}_{m}\left(t_{k}\right)$ is calculated from:

$$
\text { ' } \dot{F}_{m}\left(t_{k}\right)= \begin{cases}-\frac{F_{m}\left(t_{k-1}\right)}{\Delta t}, & \text { if } \tilde{u}_{2}\left(t_{k}\right)<-\frac{F_{m}\left(t_{k-1}\right)}{\Delta t} \\ \tilde{u}_{2}\left(t_{k}\right), & \text { if }-\frac{F_{m}\left(t_{k-1}\right)}{\Delta t} \leq \tilde{u}_{2}\left(t_{k}\right)<\frac{F_{m_{\max }}-F_{m}\left(t_{k-1}\right)}{\Delta t} \\ \frac{F_{m_{\max }}-F_{m}\left(t_{k-1}\right)}{\Delta t}, & \text { if } \tilde{u}_{2}\left(t_{k}\right) \geq \frac{F_{m_{\max }}-F_{m}\left(t_{k-1}\right)}{\Delta t}\end{cases}
$$

which is used to reconstruct the unmeasurable state variables $\left(F_{m}, C_{m}, C_{i}\right.$, and $\left.C_{s}\right)$ of the system of Eq. 2 .

\section{Implementation of the Control Law}

In this study, the manipulated inputs and jacket temperature are constrained: $0 \leq F_{m} \leq F_{m_{\max }}, 0 \leq F_{c w} \leq F_{c w_{\max }}, 0 \leq P \leq P_{\max }$, and $T_{j} \leq 363.2 \mathrm{~K}$. The constraint on jacket temperature is a safety precaution, because water is used as a heating/cooling fluid in the jacket side. In the case that jacket temperature exceeds 363.2 K, the controller sets $P=0.6 \mathrm{~kJ} \cdot \mathrm{s}^{-1}$ until jacket temperature is not greater than $363.2 \mathrm{~K}$. A key feature of this study is that during transient periods, the closed-loop process operates under active state and/or input constraints.

The following discrete-time version of the nonlinear controller is used in the computer code:

$$
\begin{aligned}
& \tilde{u}_{2}\left(t_{k}\right)=\Psi_{2}\left[v_{2}\left(t_{k}\right), F_{m}\left(t_{k-1}\right),\right. \\
& \left.\hat{C}_{m}\left(t_{k}\right), \hat{C}_{i}\left(t_{k}\right), \hat{C}_{s}\left(t_{k}\right), x_{p}\left(t_{k}\right), T\left(t_{k}\right)\right] \\
& \tilde{u}_{1}\left(t_{k}\right)=\Psi_{1}\left[v\left(t_{k}\right), F_{m}\left(t_{k}\right), \dot{F}_{m}\left(t_{k}\right), \hat{C}_{m}\left(t_{k}\right), \hat{C}_{i}\left(t_{k}\right),\right. \\
& \left.\hat{C}_{s}\left(t_{k}\right), x_{p}\left(t_{k}\right), T\left(t_{k}\right), T_{j}\left(t_{k}\right)\right]
\end{aligned}
$$

where

- $\Psi_{1}$ and $\Psi_{2}$ are defined by Eqs. 4 and 5

- $v\left(t_{k}\right)$ is calculated from

$$
v\left(t_{k}\right)=y_{s p}\left(t_{k}\right)+v^{\prime \prime}\left(t_{k}\right)
$$

The condition of Eq. 11 ensures that the monomer flow rate, $F_{m}$, does not change from its current value to a value beyond its lower or upper limit within one sampling period. Therefore, the monomer-flow-rate constraints are imposed on the rate of change of monomer flow rate rather than the flow rate itself. Once the rate of change of the monomer-stream flow rate, $\dot{F}_{m}\left(t_{k}\right)$, was calculated from Eq. 11, the monomer-stream flow rate, $F_{m}$, is calculated from:

$$
F_{m}\left(t_{k}\right)=F_{m}\left(t_{k-1}\right)+\dot{F}_{m}\left(t_{k}\right) \Delta t
$$

and the product-stream flow rate $F_{e}$ from:

$$
F_{e}\left(t_{k}\right)=1.20\left[F_{m}\left(t_{k}\right)+F_{i}\right]\left[1+\bar{\epsilon} x_{p}\left(t_{k}\right)\right]
$$

The factor 1.20 is used to ensure that the flow rate of the product stream is always greater than the sum of the flow rates of the two inlet streams, and, therefore, the liquid level in the reactor is maintained at a constant value (corresponding to $V=1.20 \times 10^{-3} \mathrm{~m}^{3}$ ). Note that the exit metering pump can handle the presence of bubbles in its suction.

After calculating $F_{m}\left(t_{k}\right)$, the manipulated input $\tilde{u}_{1}\left(t_{k}\right)$ is obtained from Eq. 8. The corresponding values of the actual manipulated inputs $P\left(t_{k}\right)$ and $F_{c w}\left(t_{k}\right)$ are calculated by using the following coordination rules:

$$
\boldsymbol{P}\left(t_{k}\right)= \begin{cases}\tilde{u}_{1}\left(t_{k}\right), & \text { if } 0 \leq \tilde{u}_{1}\left(t_{k}\right)<\boldsymbol{P}_{\max } \text { and } T_{j}\left(t_{k}\right) \leq 363.2 \mathrm{~K} \\ 0.60, & \text { if } 0 \leq \tilde{u}_{1}\left(t_{k}\right) \text { and } T_{j}\left(t_{k}\right)>363.2 \mathrm{~K} \\ \boldsymbol{P}_{\max }, & \text { if } \tilde{u}_{1}\left(t_{k}\right) \geq \boldsymbol{P}_{\max } \\ 0, & \text { if } \tilde{u}_{1}\left(t_{k}\right)<0\end{cases}
$$

$$
F_{c w}\left(t_{k}\right)= \begin{cases}\frac{-\tilde{u}_{1}\left(t_{k}\right)}{c_{w} \rho_{w}\left[T_{j}\left(t_{k}\right)-T_{c w}\right]}, & \text { if }-F_{c w_{\max }} c_{w} \rho_{w}\left[T_{j}\left(t_{k}\right)-T_{c w}\right] \leq \tilde{u}_{1}\left(t_{k}\right)<0 \\ F_{c w_{\max },} & \text { if } \tilde{u}_{1}\left(t_{k}\right)<-F_{c w_{\max }} c_{w} \rho_{w}\left[T_{j}\left(t_{k}\right)-T_{c w}\right] \\ 0, & \text { if } \tilde{u}_{1}\left(t_{k}\right) \geq 0\end{cases}
$$




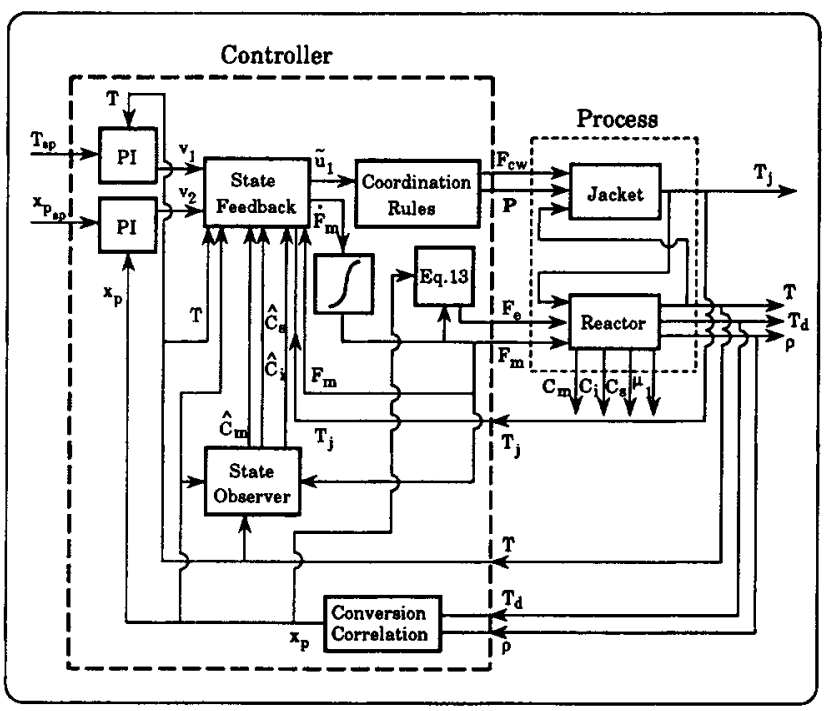

Figure 2. Block diagram of controller and process.

which indeed impose the manipulated input constraints on the manipulated input $\tilde{u}_{1}$. As given by Eq. 8 , the heat input $u_{1}\left(t_{k}\right)$ is calculated based on the constrained monomer flow rate and its rate of change $\left[F_{m}\left(t_{k}\right)\right.$ and $\left.\dot{F}_{m}\left(t_{k}\right)\right]$ : the controller calculates the net heat input after accounting for the net sensible heat that will enter the process, once the calculated $F_{m}\left(t_{k}\right)$ is implemented. The block diagram of the process and controller is shown in Figure 2.

To prevent reset windup, when an input and/or state constraint is active, the integral action of the $\mathrm{tth}$ PI controller is "shut off" by setting the integral time constant $\tau_{l_{l}}=\infty$ (because of the use of velocity form PI controllers). In more precise terms, the integral time constants are set according to:

$$
\begin{aligned}
& \tau_{l_{1}}= \begin{cases}\infty, & \text { if } \boldsymbol{P}=\boldsymbol{P}_{\text {max }} \text { or } F_{c w}=F_{c w_{\max }} \text { or } T_{j}>363.2 \mathrm{~K} \\
\beta_{11}^{1}, & \text { if otherwise }\end{cases} \\
& \tau_{I_{2}}= \begin{cases}\infty, & \text { if } F_{m}=0 \text { or } F_{m}=F_{m_{\max }} \\
\beta_{21}^{2}, & \text { if otherwise }\end{cases}
\end{aligned}
$$

The above approach for handling the constraints is intuitive. A rigorous and "optimal" way of handling constraints in MIMO systems is given by Soroush (1992). At the present time, in the presence of an active input or state constant, the theoretical properties of the closed-loop system are unknown.

On the basis of the tuning guidelines given by Soroush and Kravaris (1992), the controller adjustable parameters are chosen. The controller-parameter values are given in Table 2.

Table 2. Values of the Controller Adjustable Parameters

$\begin{array}{ll}\beta_{11}^{1}=2.1 \times 10^{3} \mathrm{~s} & \beta_{21}^{2}=2.1 \times 10^{4} \mathrm{~s} \\ \beta_{12}^{1}=2.0 \times 10^{5} \mathrm{~s}^{2} & \beta_{22}^{2}=2.0 \times 10^{7} \mathrm{~s}^{2} \\ K_{c_{1}}=1.0 \times 10^{1} & K_{c_{2}}=1.0 \times 10^{1} \\ \tau_{I_{1}}=2.1 \times 10^{3} \mathrm{~s} & \tau_{t_{2}}=2.1 \times 10^{4} \mathrm{~s}\end{array}$

\section{Experimental Procedure}

After monomer purification (inhibitor removal, drying, and vacuum distillation), the reactor is loaded with $1.2 \times 10^{-3} \mathrm{~m}^{3}$ of the monomer solution (composition by volume: $40 \%$ monomer and $60 \%$ toluene) at room temperature. The monomer feed bottles contain a solution of the same monomer-toluene composition. The concentration of the initiator solution in the initiator bottle is $0.2634 \mathrm{kmol} \cdot \mathrm{m}^{-3}$.

The above low monomer-to-solvent ratio and the conversion setpoint of 0.5 are chosen to ensure that the pressure drop across the densitometer sensor (which exceeds $2.76 \times 10^{5}$ $\mathrm{kg} \cdot \mathrm{m}^{-1} \cdot \mathrm{s}^{-2}$ at the conversion of 0.5 ) can be compensated by the circulating pump.

Note that in developing the mathematical model, all important factors contributing to polymerization reactions in bulk were accounted for, therefore, if a higher monomer-tosolvent ratio is used, the controller and its execution time (CPU time) remain the same. In other words, a simpler model can describe the dynamics of the polymerization reactor under the above low monomer-to-solvent ratio. Despite using a very detailed model, the CPU time is $0.2 \mathrm{~s}$, which is significantly less than the sampling period $(\Delta t=5 \mathrm{~s})$.

After loading the reactor with the solvent and monomer, the monomer solution in the reactor and the monomer and initiator solutions in the feed bottles are purged of oxygen (a reaction inhibitor) by bubbling nitrogen through them for one hour. A blanket of nitrogen is also maintained over reacting liquids in the reactor and feed bottles during the operation.

Finally, at time $t=0,9.8 \mathrm{gr}$ pure initiator is added to the reactor and the computer program is initialized to perform the reactor startup and then steady-state operation. Note that at time $t=0$, the reduced-order observer is initialized at the actual loading values of the concentrations $C_{m}, C_{i}$, and $C_{s}$. Our batch experimental study (Soroush and Kravaris, 1992) showed that the controller is robust (insensitive) to errors in the initialization of the observer.

\section{Controller Performance}

Through experimental runs, in the presence of active input and state constraints, the performance of the controller is evaluated. This involves studying the controller performance in performing reactor startup, tracking step changes in the setpoints, and inducing a decoupled input/output response to the closed-loop system.

\section{Reactor startup}

Figure 3a depicts the profiles of the controlled outputs from the loading instant $(t=0)$ until the reactor reaches steady-state conditions. The loading conditions are given in Table 3 . At time $t=0$, only solvent, initiator and monomer are in the reactor $\left[x_{p}(0)=0\right]$ and the reactor is at room temperature. As this figure shows, the temperature response is faster than conversion response; it takes some time for the reactor to produce sufficient amount of polymer. Under the nonlinear controller, each controlled output goes to its setpoint value and stays there.

The unusual fast conversion response is due to the overmeasured density signal during the startup period. As pointed out in our previous CSTR control study (Soroush and Kravaris, 1993), the densitometer density signal is overmeasured when 


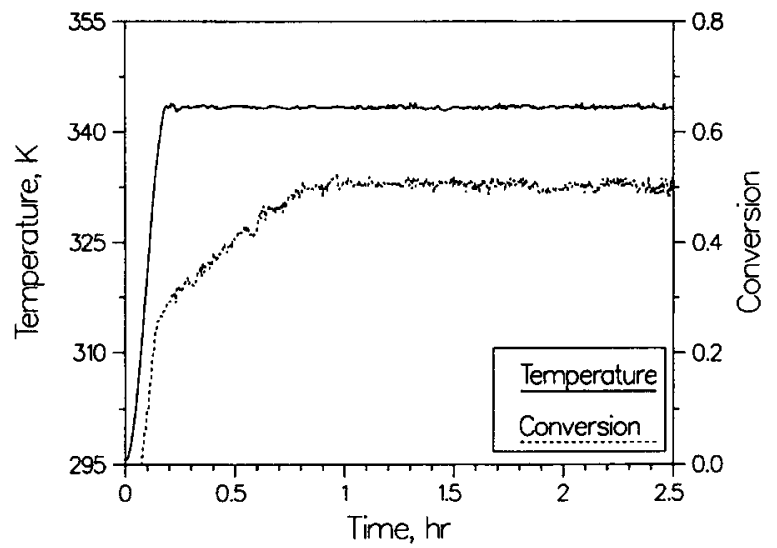

Figure 3a. Startup profiles of outputs.

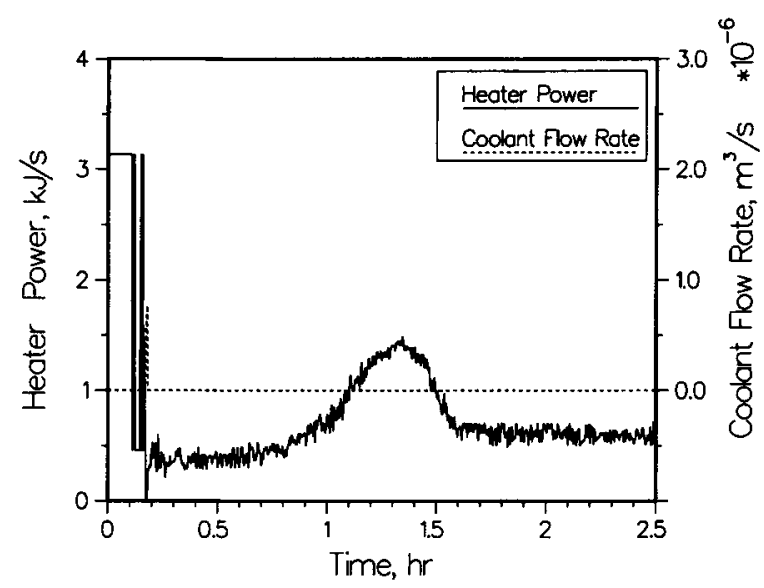

Figure 3b. Profiles of coolant flow rate and heater power corresponding to Figure 3a.

the sensor is subjected to sharp, positive temperature changes. Therefore, during the early stage of startup, the inferred conversion is higher than its actual value. This error decreases, as the rate of change in the sensor temperature decreases (as steady state is approached).

Figures $3 \mathrm{~b}, 3 \mathrm{c}$, and $3 \mathrm{~d}$ depict the corresponding profiles of the heater power $(\boldsymbol{P})$ and inlet coolant flow rate $\left(F_{c w}\right)$, monomer flow rate $\left(F_{m}\right)$, and jacket temperature $\left(T_{j}\right)$, respectively. As can be seen in Figure $3 \mathrm{~b}$, the controller initially requests maximum heater power (initially the upper constraint on the heater power is active); it tries to bring the reactor temperature to its setpoint value in a minimum time. However, after about $0.12 \mathrm{~h}$, as Figure $3 \mathrm{~d}$ shows, the jacket temperature exceeds $363.2 \mathrm{~K}$ (upper constraint on jacket temperature becomes active). The controller, according to Eq. 14, sets the heater power $\boldsymbol{P}=0.60 \mathrm{~kJ} \cdot \mathrm{s}^{-1}$, and once the jacket temperature is no longer above $363.2 \mathrm{~K}$, it sets the heater power $\boldsymbol{P}=\boldsymbol{P}_{\max }=3.13 \mathrm{~kJ} \cdot \mathrm{s}^{-1}$. This controller behavior keeps jacket temperature in the vicinity of $363.2 \mathrm{~K}$ until this high jacket temperature is no longer needed. Figure $3 \mathrm{c}$ shows that the controller initially sets the inlet monomer flow rate to zero; it initially operates the reactor in batch mode to take conversion to 0.50 in a minimum time. This controller behavior intuitively makes sense: the concentration of polymer in the reactor will

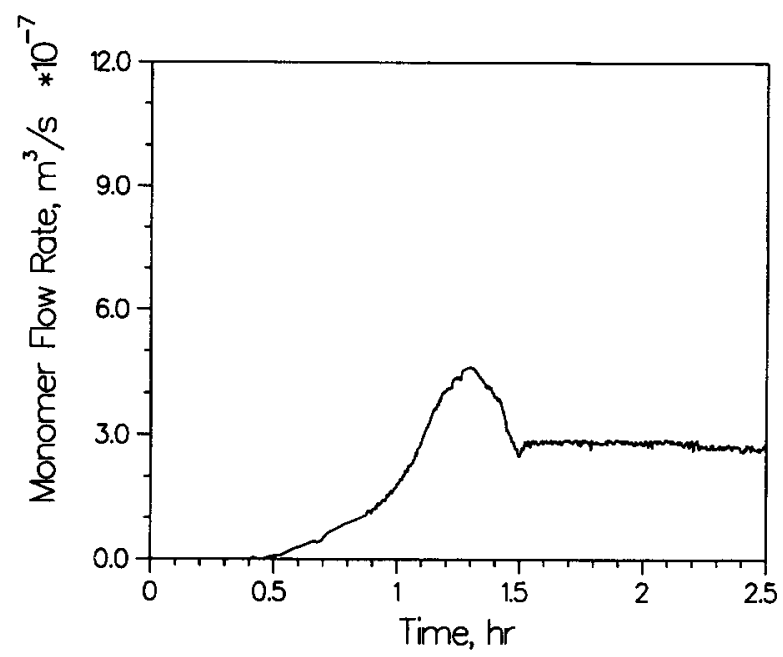

Figure 3c. Profile of monomer stream flow rate corre. sponding to Figure $3 a$.

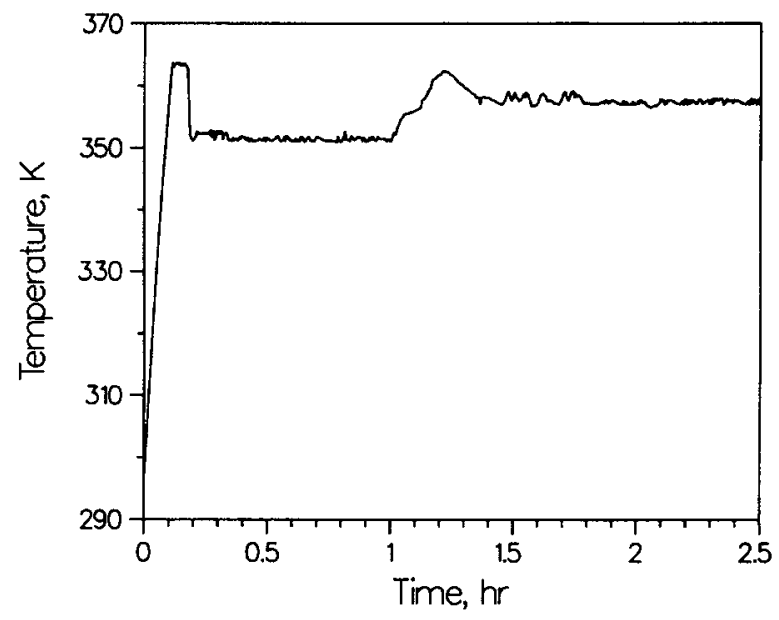

Figure 3d. Profile of jacket temperature corresponding to Figure 3a.

reach its desired steady-state value in a minimum time, if no polymer chain leaves the reactor (infinite residence time). After about half an hour of zero flow rate, the monomer flow rate increases and reaches its steady-state value.

Table 3. Operating Conditions of the CSTR

$$
\begin{aligned}
& C_{i}(0)=5.000 \times 10^{-2} \mathrm{kmol} \cdot \mathrm{m}^{-3} \\
& C_{s}(0)=5.881 \times 10^{0} \mathrm{kmol} \cdot \mathrm{m}^{-3} \\
& C_{m}(0)=3.984 \times 10^{0} \mathrm{kmol} \cdot \mathrm{m}^{-3} \\
& x_{p}(0)=0.000 \times 10^{0} \\
& T(0)=2.952 \times 10^{2} \mathrm{~K} \\
& T_{j}(0)=2.952 \times 10^{2} \mathrm{~K} \\
& C_{i_{i, s}}=2.634 \times 10^{-1} \mathrm{kmol} \cdot \mathrm{m}^{-3} \\
& C_{s_{n}}=8.986 \times 10^{\circ} \quad \mathrm{kmol} \cdot \mathrm{m}^{3} \\
& C_{s_{m v}}=5.881 \times 10^{0} \mathrm{kmol} \cdot \mathrm{m}^{-3} \\
& C_{m_{m}}=3.984 \times 10^{\mathrm{n}} \mathrm{kmol} \cdot \mathrm{m}^{-3} \\
& T_{s p}=3.432 \times 10^{2} \mathrm{~K} \\
& x_{p_{w},}=5.000 \times 10^{-1}
\end{aligned}
$$




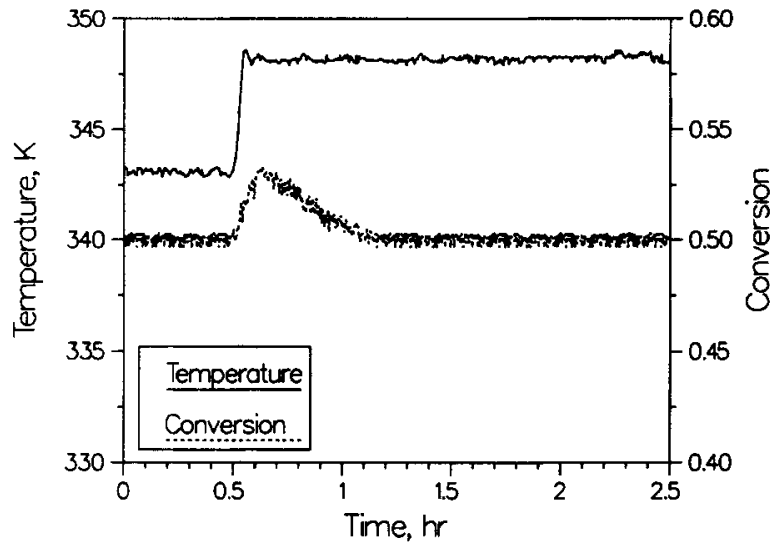

Figure 4a. Output variable responses to a step change in temperature setpoint at $t=0.5 \mathrm{~h}$.

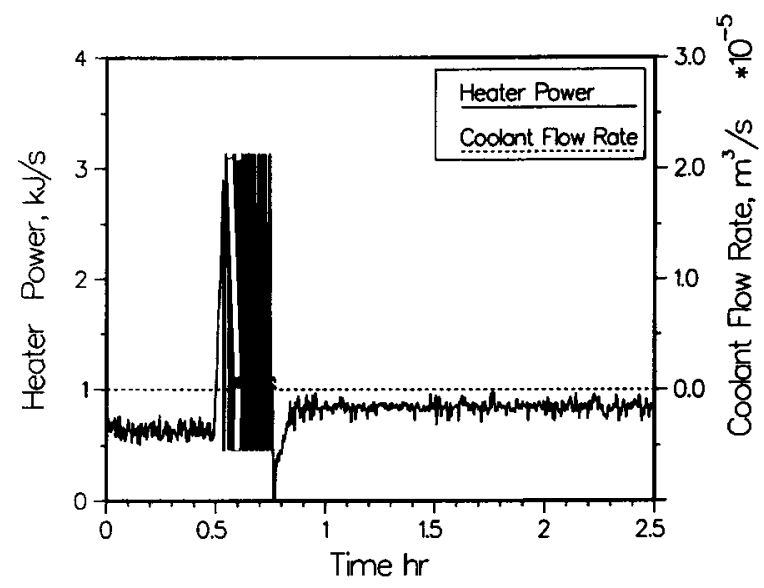

Figure 4b. Profiles of coolant flow rate and heater power corresponding to Figure 4a.

\section{Step changes in the setpoints}

Figure $4 \mathrm{a}$ depicts the profiles of the controlled outputs when there is a step change in the reactor temperature setpoint $T_{s p}$ from $343.2 \mathrm{~K}$ to $348.2 \mathrm{~K}$ at time $t=0.5 \mathrm{~h}$. The controller forces the reactor to asymptotically track this setpoint change and compensates for the effect of the increase in the reactor temperature on conversion. The corresponding profiles of the heater power $(P)$ and inlet coolant flow rate $\left(F_{c w}\right)$, monomer flow rate $\left(F_{m}\right)$, and jacket temperature $\left(T_{j}\right)$ are depicted in Figures $4 b, 4 c$, and $4 d$. Figure $4 b$ shows that the controller initially requests maximum heater power to bring the reactor temperature to its new setpoint value in a minimum time. However, after about $0.02 \mathrm{~h}$, as Figure $4 \mathrm{~d}$ shows, the jacket temperature exceeds $363.2 \mathrm{~K}$ (upper constraint on jacket temperature becomes active). The controller, according to Eq. 14, sets the heater power $\boldsymbol{P}=0.60 \mathrm{~kJ} \cdot \mathrm{s}^{-1}$, and once the jacket temperature is no longer above $363.2 \mathrm{~K}$, it sets the heater power $\boldsymbol{P}=\boldsymbol{P}_{\max }=3.13 \mathrm{~kJ} \cdot \mathrm{s}^{-1}$. This controller behavior keeps jacket temperature in the vicinity of $363.2 \mathrm{~K}$ until this high jacket temperature is no longer needed. Since the reactor has an interactive dynamics (a change in reactor temperature strongly affects the conversion), in order to compensate for this interaction (to eliminate the effect of the change in temperature on

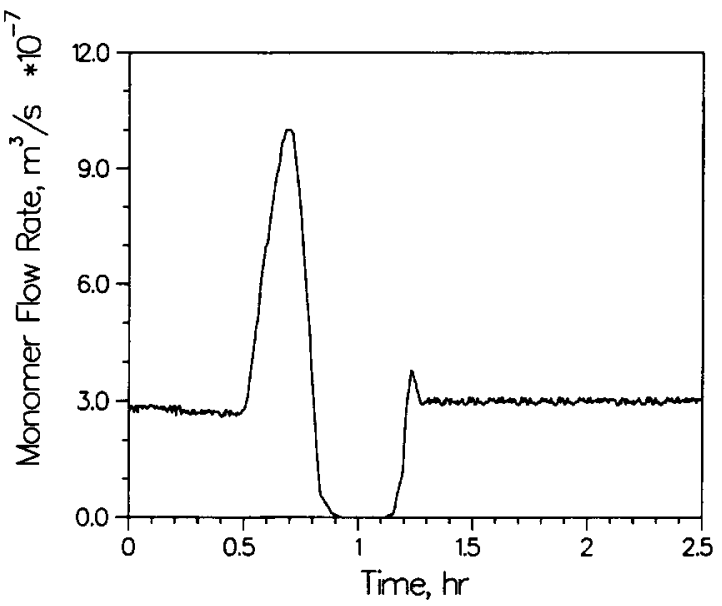

Figure 4c. Profile of monomer stream flow rate corresponding to Figure $4 a$.

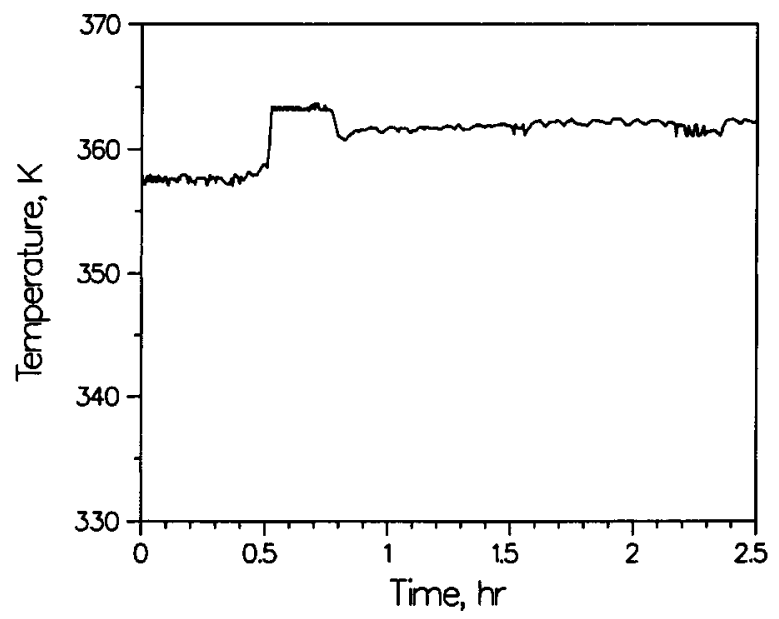

Figure 4d. Profile of jacket temperature corresponding to Figure 4a.

conversion), as shown in Figure 4c, the controller operates the reactor at a lower residence time (higher monomer flow rate). However, because the monomer flow rate calculated by the controller cannot exceed its upper limit, the controller cannot fully compensate for the effect of the temperature change on the conversion, and therefore, conversion increases. Note that the inaccuracy of the densitometer during the transient periods, during which the densitometer is not thermally stabilized (for example, during the early stages of the reactor startup and the step change in the temperature setpoint), is partially responsible for the overshoot in the conversion response (Figure 4a) and the aggressive controller action (Figures $4 b$ and $4 c$ ).

Figure 5 a depicts the profiles of the controlled outputs when there is a step change in the conversion setpoint $x_{p_{s f}}$ from 0.50 to 0.55 at time $t=0.5 \mathrm{~h}$. The controller forces the reactor to asymptotically track this setpoint change and completely compensates for the effect of the increase in conversion on the reactor temperature. As Figure $5 \mathrm{c}$ shows, the controller tries to bring conversion to its new setpoint value by increasing the reactor residence time (decreasing the monomer flow rate). In so doing, the lower limit on the monomer flow rate becomes 


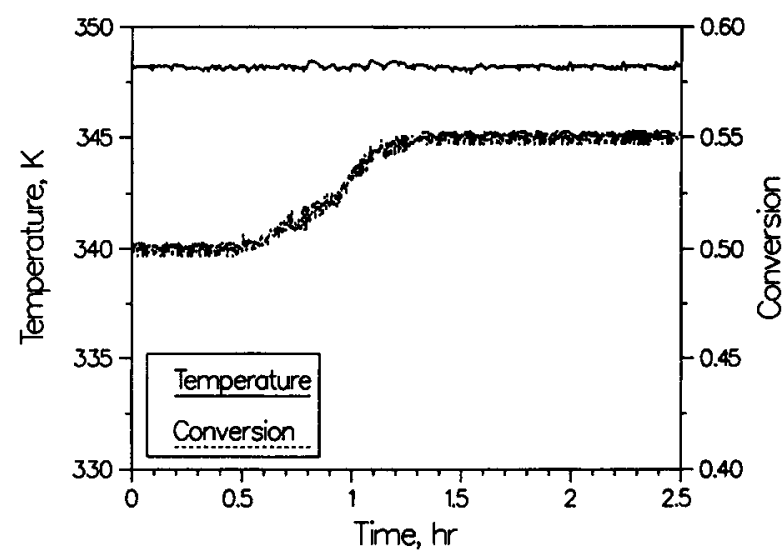

Figure 5a. Output variable responses to a step change in conversion setpoint at $t=0.5 \mathrm{~h}$.

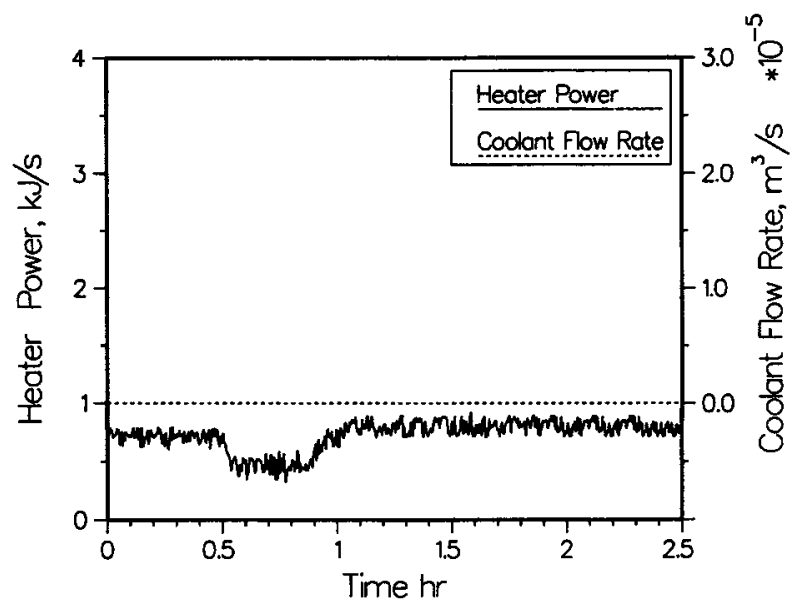

Figure 5b. Profiles of coolant flow rate and heater power corresponding to Figure 5 a.

active for a short period of time. In contrast to the previous case, the step change in the conversion setpoint does not affect the other controlled output (reactor temperature), and therefore, in this case, input/output decoupling is achieved. For this case, the corresponding profiles of the heater power $(\boldsymbol{P})$, coolant flow rate $\left(F_{c w}\right)$, monomer flow rate $\left(F_{m}\right)$, and jacket temperature $\left(T_{j}\right)$ are shown in Figures $5 \mathrm{~b}, 5 \mathrm{c}$, and $5 \mathrm{~d}$.

\section{Closed-loop input/output decoupling}

In the absence of constraints and modeling errors, the controller of Eq. 3 induces a decoupled linear input/output response to the closed-loop system (Eq. 6). In the presence of constraints and modeling errors, the ability of the controller of Eq. 3 in inducing the theoretically requested decoupled closed-loop response is shown in Figures $4 a$ and 5a (only oneway decoupling is achieved). In the case of the step change in the conversion setpoint, the decrease in the rate of sensible heat leaving the reactor (due to a lower monomer flow rate, see Figure $5 c$ ) is fully compensated by the controller (which requests a lower heater power, see Figure $5 b$ ). Therefore, the step change in the conversion setpoint does not affect the reactor temperature. However, in the case of the step change

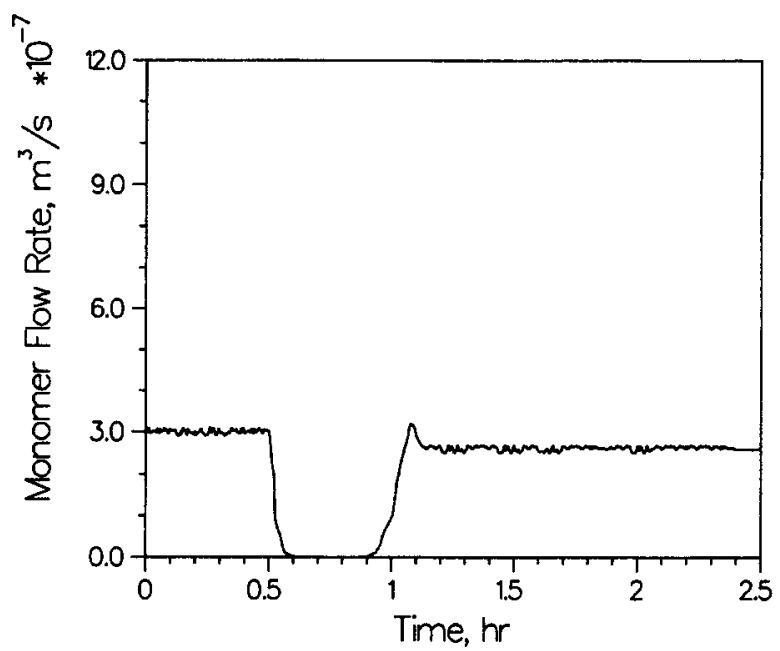

Figure 5c. Profile of monomer stream flow rate corresponding to Figure $5 \mathrm{a}$.

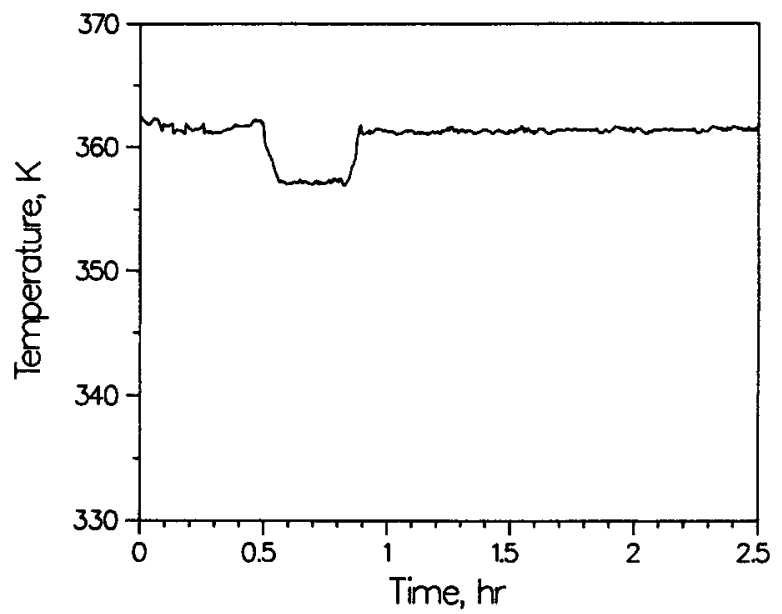

Figure 5d. Profile of jacket temperature corresponding to Figure 5 a.

in the temperature setpoint, the controller cannot fully compensate for the effect of the increase in the reactor temperature on conversion. This incomplete compensation is due to the boundedness of the controller effort (especially, the upper constraint on the monomer flow rate) and the inaccuracy of the densitometer during the periods within which the densitometer is not thermally stabilized. The one-way decoupling is also partially due to the faster speed of the temperature loop compared to that of the conversion loop (the reactor has a high heat-transfer-surface-area-to-volume ratio).

\section{Conclusions}

A controller synthesized within the GLC framework was implemented experimentally to control temperature and conversion in a pilot-size polymerization CSTR with singular characteristic matrix. In the presence of active state and input constraints, the reactor-startup and setpoint-tracking performance of the controller was studied through experimental runs. This work is an experimental application of a very recent study 
by Daoutidis and Kumar (1994) on the synthesis of feedback control systems for general multivariable nonlinear processes with singular characteristic matrix. Furthermore, it is the first real-time control study in which a MIMO nonlinear modelbased controller is applied to a polymerization reactor with singular characteristic matrix.

The presence of the active state and input constraints was treated intuitively, resulting in a satisfactory performance of the controller. A rigorous and theoretically-supported way of handling constraints is given by Soroush (1992).

A comparison of this study and our previous CSTR study (Soroush and Kravaris, 1993) shows that:

- When the rate of heat input to jacket and the flow rate of an inlet initiator stream are used as manipulated inputs, the control problem is less interactive (in an input/output sense) and does not suffer from singularity of characteristic matrix.

- When the rate of heat input to jacket and reactor residence time are used as manipulated inputs, the control problem is strongly interactive (in an input/output sense) and suffers from singularity of characteristic matrix.

- The conversion and temperature control can be achieved more effectively by manipulating the rate of heat input to jacket and reactor residence time rather than the rate of heat input to jacket and the flow rate of an inlet initiator stream.

\section{Acknowledgment}

Financial support from the National Science Foundation through the grant CTS-8912836 is gratefully acknowledged.

\section{Notation}

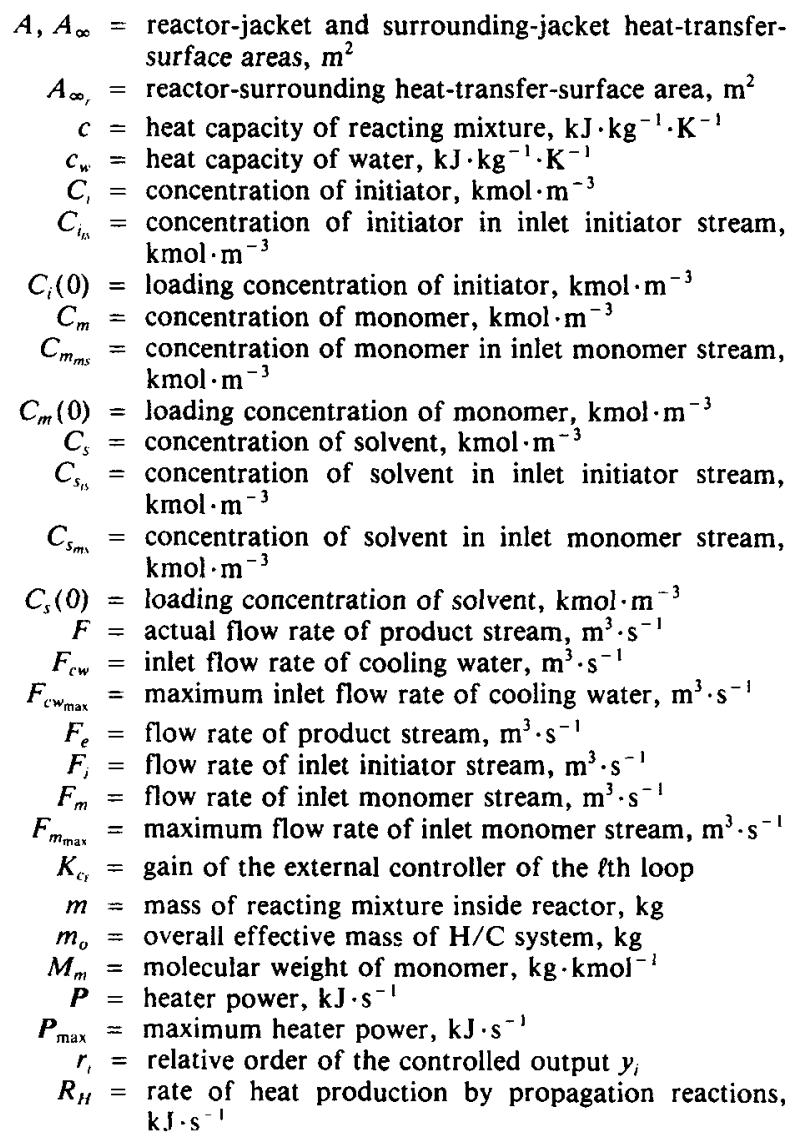

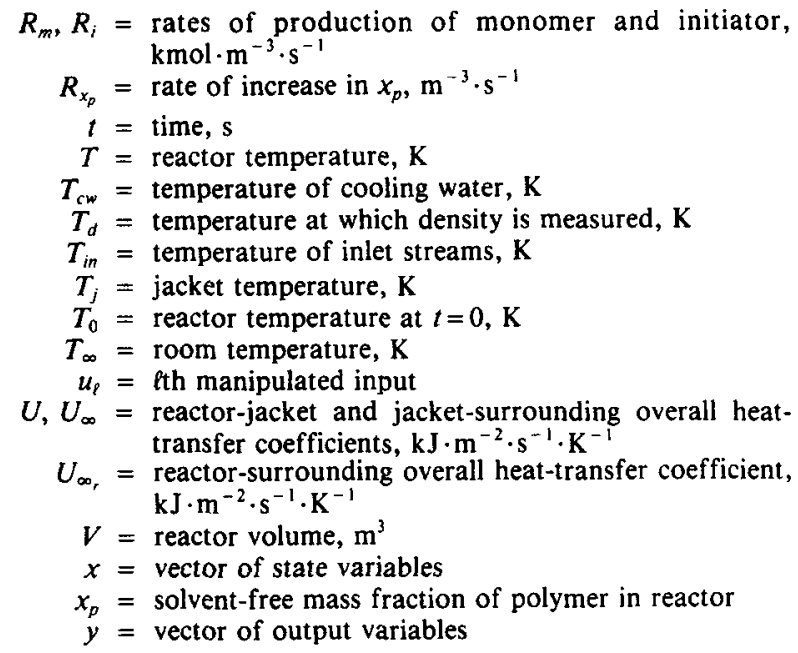

\section{Greek letters}

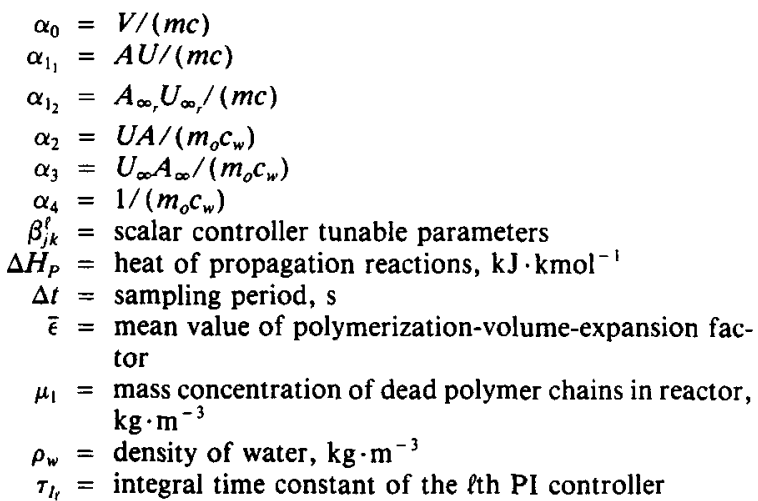

\section{Math symbols}

$L_{f} h_{i}(x)=$ Lie derivative of the scalar field $h_{i}(x)$ with respect to the vector field $f(x)$

$$
=L_{j}^{1} h_{i}(x) \triangleq \sum_{\ell=1}^{n} \frac{\partial h_{i}(x)}{\partial x_{\ell}} f_{\ell}(x)
$$

$L_{f}^{p+1} h_{i}(x)=$ Lie derivative of scalar field $L_{f} h_{i}(x)$ with respect to vector field $f(x)$

$L_{g_{j}} L_{f}^{\ell} h_{i}(x)=$ Lie derivative of scalar field $L_{f}^{q} h_{i}(x)$ with respect to vector field $g_{j}(x)$

\section{Acronyms}

AIBN = azo-bis-isobutyronitrile

GLC = globally linearizing control

MMA $=$ methyl methacrylate

$\mathrm{PI}=$ proportional-integral

\section{Literature Cited}

Amrehn, H., "Computer Control in Polymerization Industry," $A u$ tomatica, 13, 533 (1977).

Chien, D. C. H., and A. Penlidis, "On-Line Sensors for Polymerization Reactors," JMS-Rev. Macromol. Chem. Phys., C30(1), 1 (1990).

Daoutidis, P., and A. Kumar, "Structural Analysis and Output Feedback Control of Nonlinear Multivariable Processes," AIChE J., 40(4), 647 (1994).

Elicabe, G. E., and G. R. Meira, "Estimation and Control in Polymerization Reactors. A Review," Poly. Eng. \& Sci., 28, 121 (1988).

Kravaris, C., and M. Soroush, "Synthesis of Multivariable Nonlinear 
Controllers by Input/Output Linearization," $A I C h E J ., 36,249$ (1990).

MacGregor, J. F., "Control of Polymerization Reactors," Proc. of IFAC, 31 (1986).

Ray, W. H., "Modeling and Control of Polymerization Reactors," Proc. of 3rd IFAC Symposium on Dynamics and Control of Chemical Reactors, Distillation Columns and Batch Processes, College Park, MD, p. 161 (1992)

Schmidt, A. D., and W. H. Ray, "The Dynamic Behavior of Continuous Polymerization Reactors-I," Chem. Eng. Sci., 36, 1401 (1981).

Soroush, M., "Studies in Nonlinear Control and Optimal Design with Experimental Application to Polymerization Reactors," PhD Thesis, University of Michigan, Ann Arbor (1992).
Soroush, M., and C. Kravaris, "Multivariable Nonlinear Control of a Continuous Polymerization Reactor: an Experimental Study," AIChE J., 39(12), 1920 (1993).

Soroush, M., and C. Kravaris, "Nonlinear Control of a Batch Polymerization Reactor: an Experimental Study," AIChE J., 38, 1429 (1992).

Tirrell, M., R. Galvan, and R. L. Laurence, "Polymerization Reactors," in Chemical Reaction and Reactor Engineering, J. J. Carberry and A. Varma, eds., Marcel Dekker, Basel-New York, p. 735 (1987).

Manuscript received May 25, 1993, and revision received Sept. 13, 1993. 